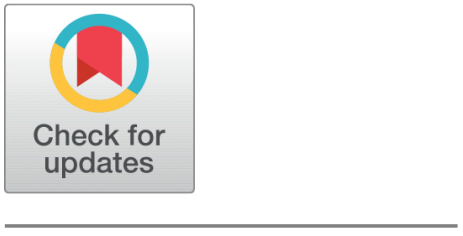

OPEN ACCESS

Received: 10.10 .2020

Accepted: 12.01.2021

Published: 01.02.2021

Citation: Ghoto AA, Talpur GHM, Kamboh SA (2021) Estimation and forecasting of the inflation, interest,literacy and unemployment rate of Pakistan using nonlinear regression models. Indian Journal of Science and Technology 14(3): 251-258. https://doi.org/ 10.17485/IJST/V14i3.1812

* Corresponding author.

Tel: 0092-333-2794950

ghotoabbas@quest.edu.pk

Funding: None

Competing Interests: None

Copyright: (c) 2021 Ghoto et al. This is an open access article distributed under the terms of the Creative Commons Attribution License, which permits unrestricted use, distribution, and reproduction in any medium, provided the original author and source are credited.

Published By Indian Society for Education and Environment (iSee)

ISSN

Print: 0974-6846

Electronic: 0974-5645

\section{Estimation and forecasting of the inflation, interest,literacy and unemployment rate of Pakistan using nonlinear regression models}

\author{
A A Ghoto ${ }^{1 *}$, G H Mir Talpur ${ }^{2}$, S A Kamboh ${ }^{1}$ \\ 1 Department of Mathematics and Statistics, QUEST, Nawabshah, 67480, Pakistan. Tel.: 0092- \\ 333-2794950 \\ 2 Department of Statistics, University of Sindh, Jamshoro, 76080, Pakistan
}

\section{Abstract}

Background/Objectives: To analyze and investigate the relationships for the inflation rate, interest rate, literacy rate and unemployment rate of Pakistan with a high level of accuracy. Methods/Statistical analysis: Method of nonlinear least squares have been adopted to fit the nonlinear regression models to estimate the present and future trends for the inflation rate, interest rate, literacy rate and unemployment rate of Pakistan based on the data from the year 2000 to 2019. Various nonlinear regression models were tested by changing their degree and number of coefficients. For each trial, the goodness of fit was set at a 95\% confidence level. The best regression models were selected on basis of goodness of fit, the correlation with the present data and the logical trend of future forecasts. Findings: The proposed nonlinear regression models are quite different from the conventional linear and nonlinear polynomial regression models. The fitted and forecasting graphs show very realistic results that can be used by policymakers with good accuracy. Novelty/Applications: Since the periodic abrupt changes in the quantitative response variables like inflation rate, interest rate, literacy rate and the unemployment rate of Pakistan have been smoothly incorporated; therefore, the government or other socio-economic practitioners may use the results for future planning and management of the resources depending upon these factors.

Keywords: Inflation rate; literacy rate; interest rate; unemployment rate; nonlinear regression; forecasting

\section{Introduction}

The economist and policymakers are often keen to know the trends and correlations of the inflation rate, interest rate, literacy rate and unemployment rate that may help them to analyze the economic growth of a country. Inflation refers to a situation where the supply of money exceeds its demand or prices of commodities increase steadily. Often, inflation puts adverse consequences on the purchasing power of the people, 
macroeconomic instabilities and overvalued exchange rates which have a negative effect on exports ${ }^{(1)}$. The level of inflation plays a significant role when making price-setting judgments or when negotiating for wages. The variation in the availability of goods and services used as inputs in the production affects the final price of goods and services in the economy, consequently changing the rate of inflation ${ }^{(2)}$. The measure of inflation is often derived from a rise in a broad price index expressing the overall price level for goods and services in the economy. Some most common examples of broad price indices comprise the Consumer Price Index (CPI), the Personal Consumption Expenditures Price Index (PCEPI) and the GDP (Gross Domestic Product) deflator. Typically, the CPI values are computed by using the Laspeyres formula ${ }^{(3,4)}$. Interest is the payment from a borrower to lender of payment above the repayment of the amount borrowed or it may be the payment against the saving certificates of banks. The interest rate is considered to be an important financial factor that affects the decisions of policymakers, professional investors and consumers; it also helps to understand the financial progress and changes in economic policy ${ }^{(5,6)}$. In most situations, the interest rate is influenced by the forces of demand and supply, inflation, and government policies. Generally, literacy is the ability to read, write and use language, numbers, symbols, and other useful information ${ }^{(7)}$. The literacy rate is normally determined by using the data consisting of the number of people of the age group 15-24 years who are literate and the total population in the same age group. Among the different parts of the world, the countries having higher literacy rates exhibited lower poverty ratios ${ }^{(8)}$. Unemployment refers to a socio-economic situation where the individuals are willing to work but are unable to get a job. Unemployment is a worldwide problem and usually, the countries with high unemployment rates suffer from various social, political, and economical instabilities that lead to poverty, health diseases and high crime rates ${ }^{(9)}$. The above mentioned four economic factors are normally calculated by the following individual Equations:

$$
\begin{gathered}
I_{r}=\left(\frac{c_{2}-c_{1}}{c_{1}}\right) \times 100 \\
i_{n}=i_{r}+p_{e}+r_{p}+l_{p} \\
L_{r}=\frac{N_{L}}{P_{L}} \times 100 \\
U_{r}=\frac{u_{p}}{T_{l}} \times 100
\end{gathered}
$$

where $I_{r}$ is the annual interest rate, $c_{1}$ and $c_{2}$ are the CPI in two consecutive years respectively; $i_{n}$ is the nominal interest rate, $i_{r}$ is the risk-free return to capital, $p_{e}$ is the expected inflation rate, $r_{p}$ is a risk premium and $l_{p}$ is a liquidity; $L_{r}$ is the literacy rate, $N_{L}$ is the number of literate people in the age group in the year and $P_{L}$ is the total population of the same age group in the year; $U_{r}$ is the unemployment rate, $u_{p}$ is the number of unemployed people and $T_{l}$ is the total labor force.

In literature, a variety of techniques have been proposed for the forecasting of these economic factors that range from the simple linear models to more sophisticated nonlinear or time series models. Such models have often been used to either study the time-dependent behavior of each of the individual factors or the mutual dependence of one or many variables on another set of variables.

Pakistan is the $6^{\text {th }}$ largest population in the world having about 65 million labors that makes it the $10^{\text {th }}$ largest labor force. Due to the rapid increase in population and fewer job opportunities the government needs to properly forecast economic factors like inflation, interest, literacy and unemployment to construct future policies. In order to analyze the impact of such factors on the socio-economic growth of Pakistan many studies including ${ }^{(10-18)}$ have demonstrated the quantitative models. For instance, a recent study ${ }^{(19)}$ investigated the asymmetric relationship between the unemployment rate and poverty in Pakistan using annual data from 1984 to 2016 by employing a nonlinear Autoregressive Distributed Lag (ARDL) co-integration approach. Their results suggested that the linear models on poverty in relation to unemployment may mislead the inference, therefore the academicians and policymakers must consider nonlinear regression models for better policy making. Thus, in most cases, the multiple linear regression models or the time series regression models have been worked out having their own merits and demerits. The nonlinear regression models may best fit the fluctuations in the data series. Therefore, this study is aimed to propose the nonlinear regression models based on methods of the nonlinear least squares. 


\section{Materials and Methods}

In order to construct the statistically and logically feasible nonlinear models for the time-dependent inflation rate, interest rate (in Pakistan, it is specifically termed as Karachi interbank offered rate, commonly known as Kibor rate) literacy rate and the unemployment rate the relevant secondary data from 2001 to 2019 was collected from the different sources like Pakistan Bureau of Statistics, International Labor Organization and World Bank ${ }^{(20-22)}$.

The method of nonlinear least squares is applied to fit the data ${ }^{(23-25)}$. A variety of non-linear regression models such as polynomial, rational, exponential, power, Fourier, Gaussian, the sum of sines or cosines and other custom equations were worked out. The goodness and statistical significance of each of the nonlinear regression relations were analyzed for obtaining the best forecasting model. The parameters were tuned repeatedly not only to fit the data but also to construct the possible fluctuations based on past data. From the extensive regression analysis; for the interest rate $I_{r}$ the sum of sines model with five terms was found to be the best fit. Similarly, for interest rate $K_{r}$ (Kibor), literacy rate $L_{r}$, and the unemployment rate $U_{r}$ the Fourier model with two general terms, the sum of sines model with two general terms and a mix of Gaussian model with two general terms and other custom expressions were found to be the best fit respectively. The individual fitted nonlinear regression models of interest rate, literacy rate and unemployment rate are given by the Equations (5-8) respectively as follows,

$$
\begin{gathered}
I_{r}(t)=a_{1} \sin \left(b_{1}(t)+c_{1}\right)+a_{2} \sin \left(b_{2}(t)+c_{2}\right)+a_{3} \sin \left(b_{3}(t)+c_{3}\right) \\
+a_{4} \sin \left(b_{4}(t)+c_{4}\right)+a_{5} \sin \left(b_{5}(t)+c_{5}\right)+a_{6} \sin \left(b_{6}(t)+c_{6}\right) \\
K_{r}=a_{0}+a_{1} \cos (t w)+b_{1} \sin (t w)+a_{2} \cos (2 t w)+b_{2} \sin (2 t w) \\
L_{r}(t)=a_{1} \sin \left(b_{1} t+c_{1}\right)+a_{2} \sin \left(b_{2} t+c_{2}\right) \\
U_{r}(t)=a_{0}+a_{1} e^{-\left((t-b) / c_{1}\right)^{2}}+a_{2} e^{-\left(\left(t-b_{2}\right) / c_{2}\right)^{2}}+a e^{b t}+c e^{t d}+a_{1} \cos (t w)+b_{1} \sin (t w)+a_{1} \sin \left(b_{1} t+c_{1}\right)+a t^{b}+c
\end{gathered}
$$

where $t \geq 1$ The list of all the coefficients used in Eq. (5) representing inflation rate and their 95\% confidence intervals is given in Table 1 and the corresponding goodness metrics such as sum of squares of error (SSE), root mean square error (RMSE), coefficient of determination $\left(\mathrm{R}^{2}\right)$ and the adjusted $\mathrm{R}^{2}$ are given in Table 2. From the Table 2 it can be seen that the inflation rate predicted by Eq. (5) has very little error with respect to the observed data and is highly correlated with 99.75 value of the coefficient of determination. In the same way, the associated coefficients and the goodness of fit are involved in $K_{r}, L_{r}$ and $U_{r}$ are given in Tables 3, 4, 5, 6, 7 and 8 respectively.

Table 1. List of estimated coefficients for the inflation rate, $\mathrm{I}_{r}$ with $95 \%$ confidence intervals.

\begin{tabular}{ll}
\hline Estimated Coefficients of the model & $95 \%$ confidence bounds \\
\hline a $=12.67$ & $(-1.771 \mathrm{e}+05,1.771 \mathrm{e}+05)$ \\
$\mathrm{b} 1=0.004903$ & $(-127.4,127.4)$ \\
$\mathrm{c} 1=2.347$ & $(-1.42 \mathrm{e}+04,1.421 \mathrm{e}+04)$ \\
a2 $=4.79$ & $(-129.1,138.7)$ \\
$\mathrm{b} 2=0.4514$ & $(-4.274,5.176)$ \\
c2 $=3.478$ & $(-41.8,48.76)$ \\
a3 $=1.424$ & $(-13,15.85)$ \\
b3 $=1.368$ & $(-2.09,4.826)$ \\
c3 $=0.8559$ & $(-24.03,25.75)$ \\
a4 $=1.193$ & $(-3.393,5.78)$ \\
b4 $=2.793$ & $(2.068,3.518)$ \\
c4 $=-4.787$ & $(-12.09,2.511)$ \\
a5 $=2.067$ & $(-3.025,7.159)$ \\
b5 $=2.165$ & $(1.149,3.18)$ \\
c5 $=2.013$ & $(-7.628,11.65)$ \\
a6 $=1.506$ & $(-11.4,14.42)$ \\
b6 $=1.561$ & $(-1.638,4.761)$ \\
c6 $=1.172$ & $(-22.7,25.05)$ \\
\hline
\end{tabular}


Table 2. Goodness of fit for inflation rate, $\mathrm{I}_{r}$.

\begin{tabular}{llll}
\hline SSE & RMSE & R-square & Adjusted R-square \\
\hline 0.7312 & 0.8551 & 0.9975 & 0.9548 \\
\hline
\end{tabular}

Table 3. List of estimated coefficients for the interest rate, $\mathrm{K}_{r}$ with $96 \%$ confidence intervals.

\begin{tabular}{ll}
\hline Estimated Coefficients of the model & $95 \%$ confidence bounds \\
\hline a $0=9.916$ & $(9.019,10.81)$ \\
a $1=-1.284$ & $(-4.913,2.345)$ \\
b1 $=1.152$ & $(0.3231,1.98)$ \\
a2 $=2.059$ & $(0.8312,3.286)$ \\
b2 $=-1.171$ & $(-6.003,3.661)$ \\
w $=0.2601 ;$ & $(0.1774,0.3428)$ \\
\hline
\end{tabular}

Table 4. Goodness of fit for inflation rate, $\mathrm{K}_{r}$.

\begin{tabular}{llll}
\hline SSE & RMSE & R-square & Adjusted R-square \\
\hline 10.71 & 0.9078 & 0.902 & 0.8643 \\
\hline
\end{tabular}

Table 5. List of estimated coefficients for the literacy rate, $\mathrm{L}_{r}$ with $96 \%$ confidence intervals.

\begin{tabular}{ll}
\hline Estimated Coefficients of the model & $95 \%$ confidence bounds \\
\hline $\mathrm{a} 1=192$ & $(-1.429 \mathrm{e}+04,1.467 \mathrm{e}+04)$ \\
$\mathrm{b} 1=0.03826$ & $(-1.882,1.958)$ \\
$\mathrm{c} 1=-0.1683$ & $(-12.44,12.1)$ \\
$\mathrm{a} 2=85.24$ & $(-5982,6152)$ \\
$\mathrm{b} 2=0.07992$ & $(-2.09,2.25)$ \\
$\mathrm{c} 2=2.144$ & $(-11.36,15.64)$ \\
\hline
\end{tabular}

Table 6. Goodness of fit for literacy rate, $\mathrm{L}_{r}$.

\begin{tabular}{llll}
\hline SSE & RMSE & R-square & Adjusted R-square \\
\hline 2.127 & 0.7404 & 0.9842 & 0.9781 \\
\hline
\end{tabular}

Table 7. List of estimated coefficients for the unemployment rate, $\mathrm{U}_{r}$ with $96 \%$ confidence intervals.

\begin{tabular}{ll}
\hline Estimated Coefficients of the model & $95 \%$ confidence bounds \\
\hline $\mathrm{a}=3.876$ & $(-364.5,372.2)$ \\
$\mathrm{a} 0=-5.894$ & $(-1.253 \mathrm{e}+08,1.253 \mathrm{e}+08)$ \\
$\mathrm{a} 1=-1.466$ & $(-5.417,2.484)$ \\
$\mathrm{a} 2=-1.308$ & $(-7.862 \mathrm{e}+06,7.862 \mathrm{e}+06)$ \\
$\mathrm{b}=-0.6875$ & $(-49.69,48.32)$ \\
$\mathrm{b} 1=0.7476$ & $(0.3483,1.147)$ \\
$\mathrm{b} 2=-103.5$ & $(-3.358 \mathrm{e}+08,3.358 \mathrm{e}+08)$ \\
$\mathrm{c}=5.525$ & $(-6.227 \mathrm{e}+07,6.227 \mathrm{e}+07)$ \\
$\mathrm{c} 1=0.4822$ & $(-4.638,5.602)$ \\
$\mathrm{c} 2=80.25$ & $(-2.018 \mathrm{e}+08,2.018 \mathrm{e}+08)$ \\
$\mathrm{d}=0.00156$ & $(-1.509 \mathrm{e}+04,1.509 \mathrm{e}+04)$ \\
$\mathrm{w}=0.8774$ & $(0.6223,1.132)$ \\
\hline
\end{tabular}

Table 8. Goodness of fit for literacy rate, $\mathrm{L}_{r}$.

\begin{tabular}{llll}
\hline SSE & RMSE & R-square & Adjusted R-square \\
\hline 1.92 & 0.5295 & 0.9159 & 0.7837 \\
\hline
\end{tabular}




\section{Results and Discussion}

The inflation rate, interest rate (Kibor), literacy rate and unemployment rates of Pakistan from the fiscal year 2001 to 2019 have been modeled and compared with the observed values of each variable. Using the modeled equations the forecasting rates for the next ten years from 2020 to 2029 has been smoothly determined. Figure 1 shows the observed (measured) inflation rate of Pakistan and the fitted inflation rate from the $1^{\text {st }}$ fiscal year to the $19^{\text {th }}$ fiscal year of $21^{\text {st }}$ century. The fitted values are very close to the observed values also show the smoothness with respect to time. The next ten years forecasting results exhibit a smooth trend that fluctuates approximately between inflation rates 6 to 15. Thus, on the basis of the last 19 years data and the fitted model (Eq.5) the inflation rate in Pakistan is expected to reach a height of about 15\% in 2023 than expected to decrease smoothly by 2029 with some rise and fall. Figure 2 compares the measured interest rate and fitted model (Eq. 6), it also illustrates the ten years forecasting of the interest rate. The proposed model estimates that the interest rate in Pakistan is expected to increase between 2023 and 2024 that may remain in the range of about $4 \%$ in the next 10 years. Similarly, the literacy rate fitted by Eq. 7 is compared with the observed data and is demonstrated by Figure 3 . The next ten years forecast reveals that the literacy rate of Pakistan is expected to increase smoothly about from $59 \%$ to $73 \%$. The geometric behavior of the fitted model for literacy rate appears very analogous to the observed data. Finally, last but the most important economic factor viz. the unemployment rate of Pakistan is estimated by Eq. 8 and is displayed in Figure 4. The estimated model (Eq. 8) shows a very good agreement with the existing data and the ten years forecasting of the unemployment rate trends also preserves the fluctuations as can be seen in the past data. The forecast curve exposes that the unemployment rate in Pakistan is expected to be higher between the years 2023 and 2024. In the next ten years, the range of unemployment is expected to be about 4.5. The overall analysis of the modeling and forecasting of the four economic factors such as inflation rate, interest rate, literacy and unemployment rate is concluded in the next section.

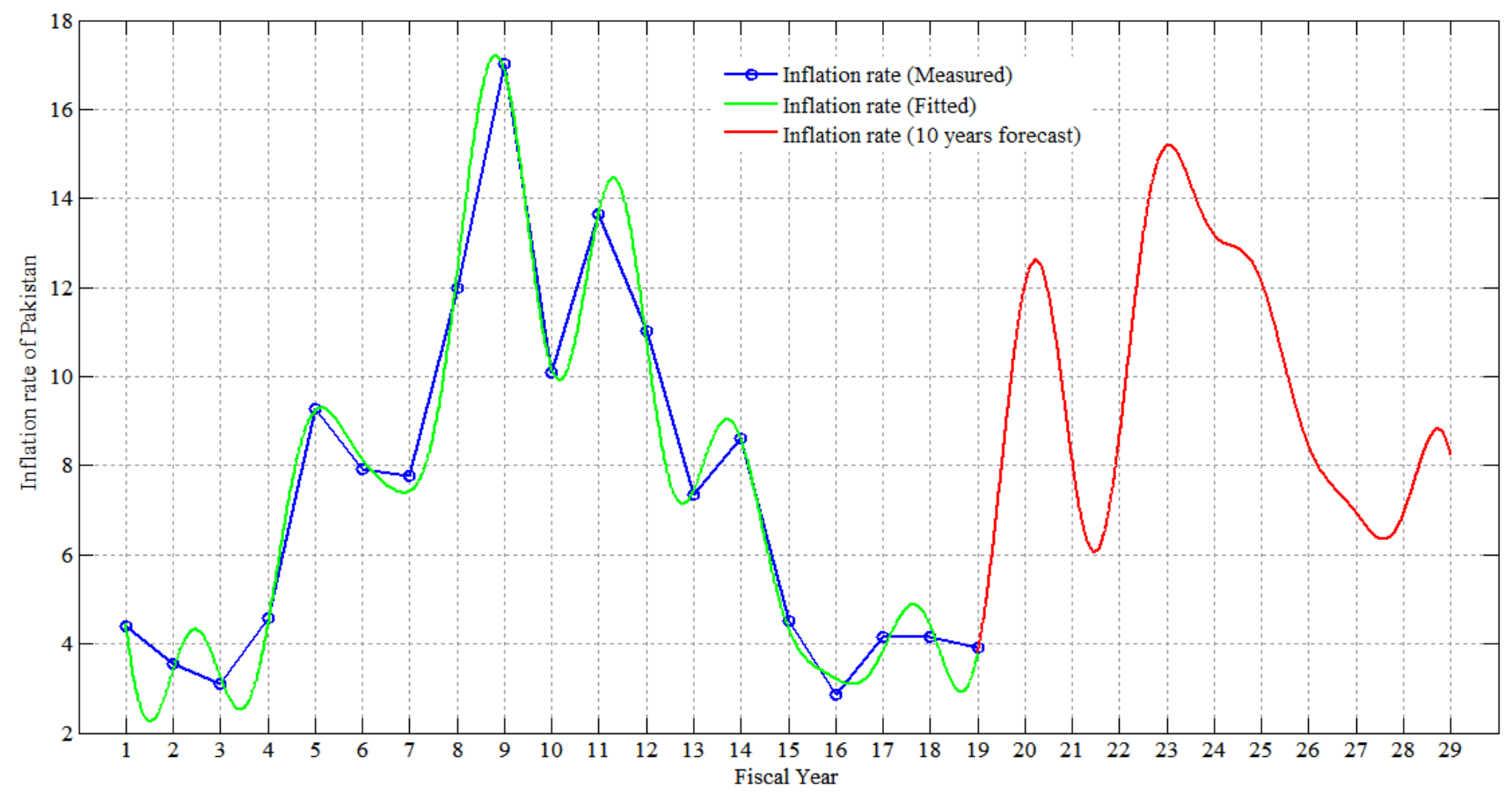

Fig 1. Estimation and ten years forecasting (from 2020 to 2029) of Inflation rate of Pakistan 


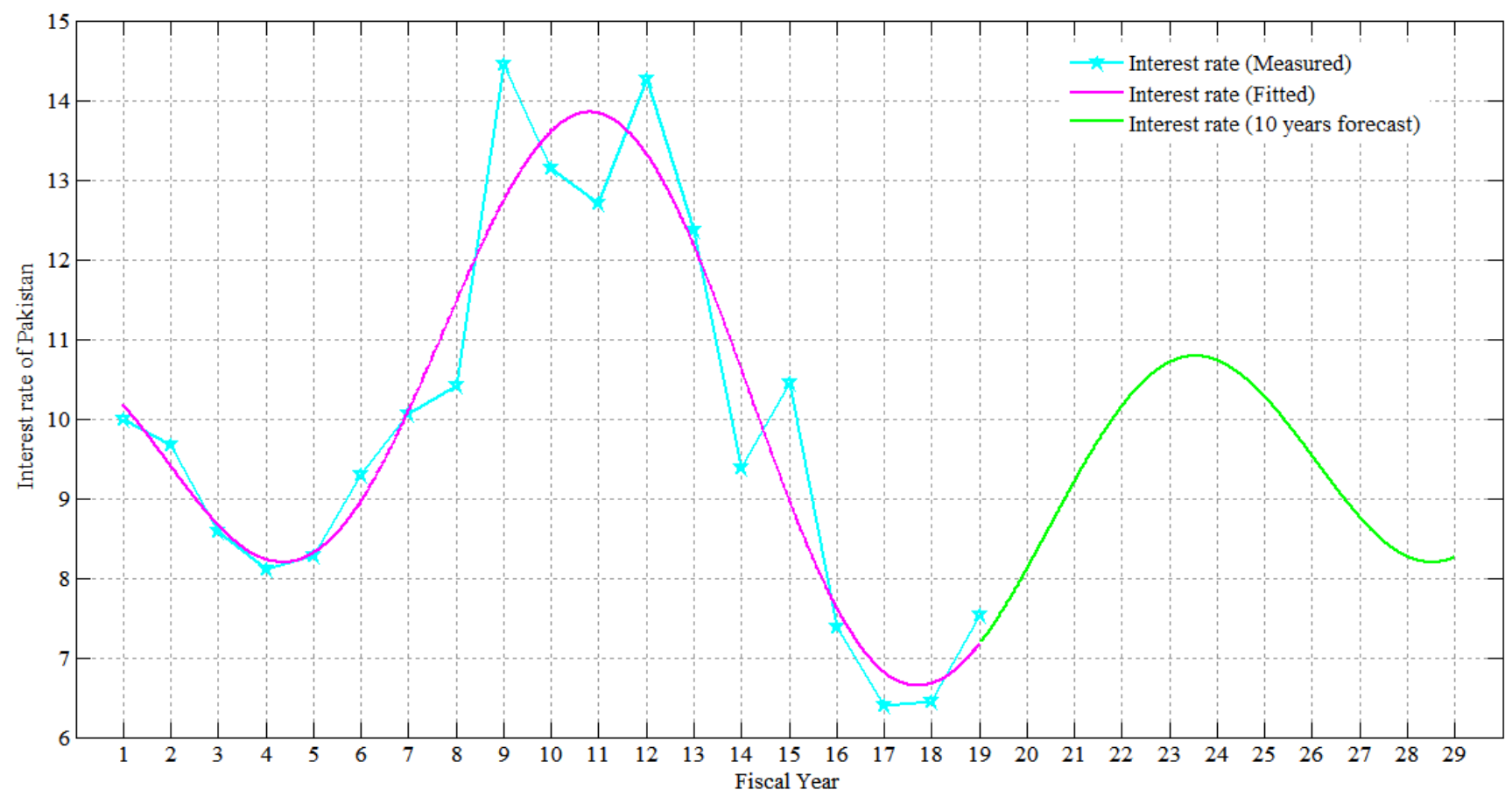

Fig 2. Estimation and ten years forecasting (from 2020 to 2029) of Interest rate ofPakistan

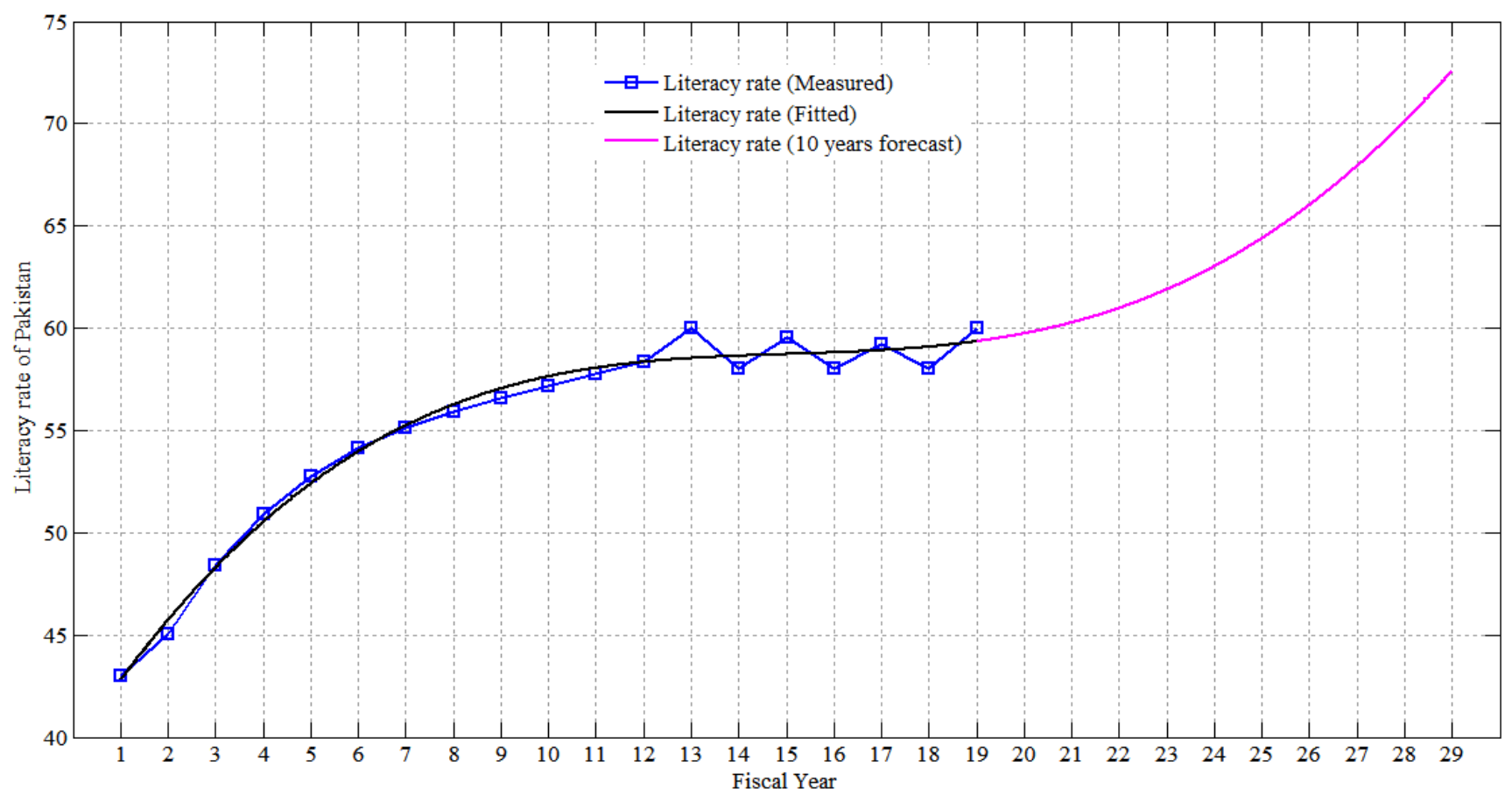

Fig 3. Estimation and ten years forecasting (from 2020 to 2029) of Literacy rate of Pakistan 


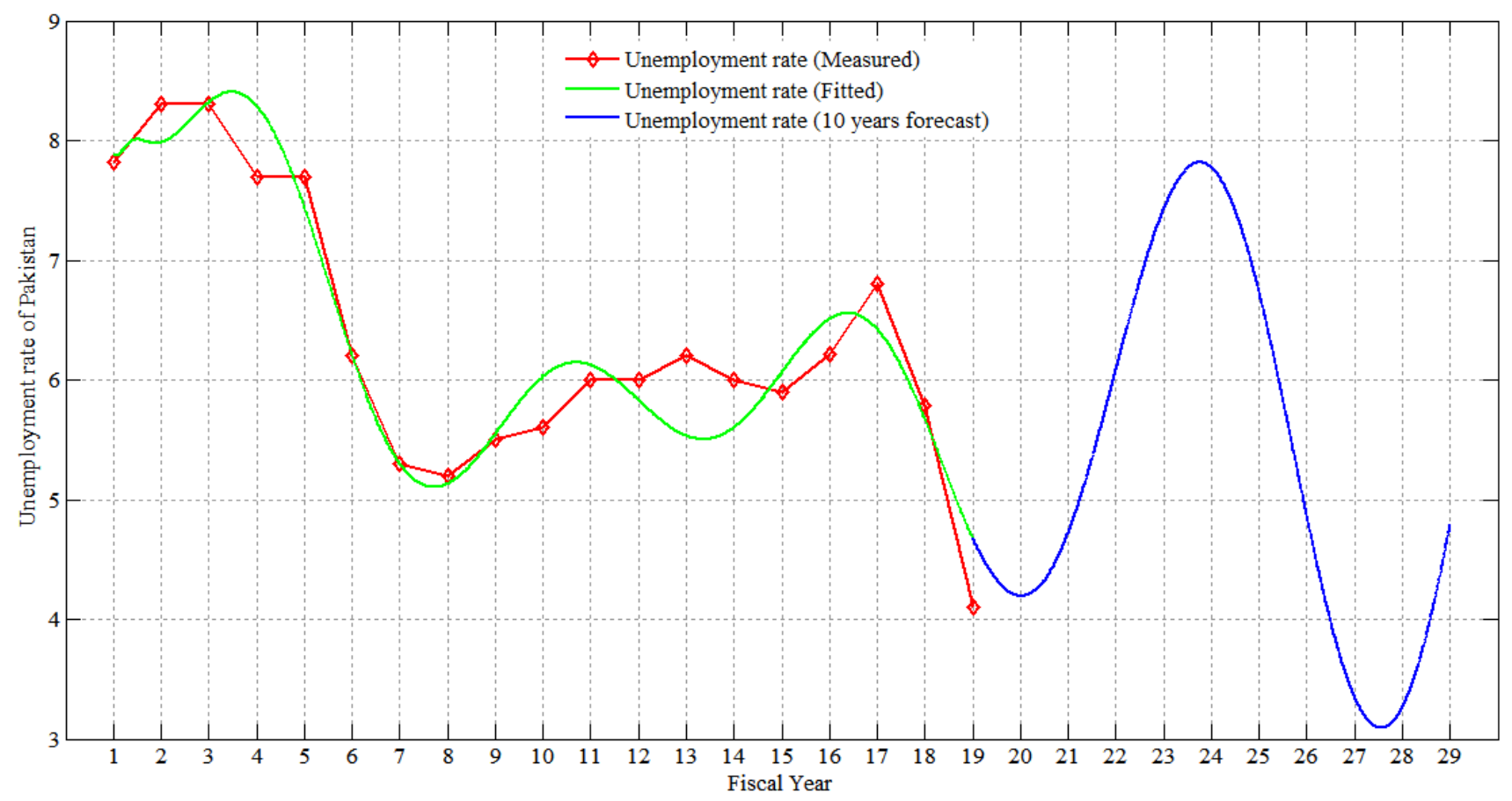

Fig 4. Estimation and ten years forecasting (from 2020 to 2029) of unemployment rate of Pakistan

\section{Conclusion}

Method of non-linear least squares was employed to fit the best regression models for the inflation rate, interest rate (Kibor), literacy rate and unemployment rate of Pakistan. Various types of nonlinear algebraic and transcendental functions were worked out. After extensive regression analysis, it was found that the sum of sines model with five general terms, the Fourier model with two general terms, the sum of sines model with two general terms and a mix of the Gaussian model and other custom expressions are the finest types of models for the inflation rate, interest rate, literacy rate and the unemployment rate of Pakistan respectively. The next ten years forecasting trends have shown that the inflation rate, interest rate, and unemployment rate are expected to be higher in the years 2023 and 2024, while the literacy rate is expected to be optimistic in the next ten fiscal years. As the high inflation rate, interest rate and unemployment rate put a negative impact on the economy of any nation, therefore, the government should take necessary actions to reduce the expected and unwanted variations in these socio-economic factors. The future work will focus on the modeling of the interrelationships among inflation rate, interest rate (Kibor), literacy rate and the unemployment rate of the Pakistan for first few decades of $21^{\text {st }}$ century.

\section{Acknowledgement}

We acknowledge the University of Sindh, Jamshoro and the Quaid-e-Awam University of Engineering, Science and Technology, Nawabshah for providing the facilities and resources to conduct this research.

\section{References}

1) Khan REA, Gill AR. Determinants of Inflation: A Case of Pakistan (1970-2007). Journal of Economics. 2010;1(1):45-51. Available from: https: //doi.org/10.1080/09765239.2010.11884923.

2) Unemployment and Inflation: Implications for Policymaking. 2016. Available from: https://www.everycrsreport.com/reports/R44663.html.

3) Kiley MJ. Estimating the common trend rate of inflation for consumer prices and consumer prices excluding food and energy prices. 2008. Available from: https://www.federalreserve.gov/pubs/feds/2008/200838/200838pap.pdf.

4) Msokwa ZE. Fixed basket Laspeyres' method compared to modified Laspeyres' method in computing Consumer Price Indices. Dar Es Salaam. Dar Es Salaam. 2012. Available from: https://www.unece.org/fileadmin/DAM/stats/documents/ece/ces/ge.22/2016/Session_5_IMF_Fixed_Basket_Indexes.pdf.

5) Mahmood Y, Bokhari R, Aslam M, M. Trade-Off between Inflation, Interest and Unemployment Rate of Pakistan: A Cointegration Analysis. Pakistan Journal of Commerce and Social Sciences. 2013;7(3):482-492. Available from: http://www.jespk.net/publications/140.pdf. 
6) Dua P, Raje N, Sahoo S. Forecasting Interest Rates in India. Margin: The Journal of Applied Economic Research. 2008;2(1):1-41. Available from: https://dx.doi.org/10.1177/097380100700200101.

7) "Literate." Merriam-Webster.com. Merriam-Webster, n.d. Web. 19 Aug. 2014. 2014. Available from: https://www.merriam-webster.com/dictionary/ literate.

8) Singh R. Female literacy and economic development in India. Rupkatha Journal on Interdisciplinary Studies in Humanities. 2016;8(2):64-70. Available from: http://dx.doi.org/10.21659/rupkatha.v8n2.07.

9) USMAN SA. Unemployment and poverty as sources and consequence of insecurity in Nigeria: The Boko Haram insurgency revisited. African Journal of Political Science and International Relations. 2015;9(3):90-99. Available from: https://dx.doi.org/10.5897/ajpsir2014.0719.

10) Ilyas M, Khan MA. Democracy versus Dictatorship: An Empirical Investigation of Determinants of Unemployment. Pakistan Business Review. 2019;20(3):525-534. Available from: http://dx.doi.org/10.22555/pbr.v20i3.631.

11) Maqbool MS, Sattar TMA, Bhalli MN. Determinants of Unemployment: Empirical Evidences from Pakistan. Pakistan Economic and Social Review. 2013;51(2):191-207. Available from: https://www.jstor.org/stable/24398836.

12) Aurangzeb, Asif K. Factors Effecting Unemployment: A Cross Country. International Journal of Academic Research in Business and Social Sciences. 2013;3(1):219-230. Available from: https://doi.org/10.1111/1467-8268.12250.

13) Khan REA, Gill AR. Determinants of Inflation: A case of Pakistan (1970-2007). Journal of Economics. 2010;1(1):45-51. Available from: https: //doi.org/10.1080/09765239.2010.11884923.

14) Ali A, Rehman HU. Macroeconomic Instability and Its Impact on Gross Domestic Product: An Empirical Analysis of Pakistan. Pakistan Economic and Social Review. 2015;53(2):285-316. Available from: https://mpra.ub.uni-muenchen.de/82496/1/MPRA_paper_82496.pdf.

15) Cheema AR, Atta A. Economic determinants of unemployment in Pakistan: Co-integration analysis. International Journal of Business and Social Science. 2014;5(3):209-221. Available from: https://www.researchgate.net/publication/265161307_Economic_Determinants_of_Unemployment_in_Pakistan_ Co-integration_Analysis.

16) Aqil M, Qureshi MA, Ahmed RR, Qadeer S. Determinants of Unemployment in Pakistan. International Journal of Physical and Social Sciences. 2014;4(4):676-682. Available from: https://www.researchgate.net/publication/261285461_Determinants_of_Unemployment_in_Pakistan.

17) Jalil A, Idrees M. Modeling the impact of education on the economic growth: Evidence from aggregated and disaggregated time series data of Pakistan. Economic Modelling. 2013;31:383-388. Available from: https://dx.doi.org/10.1016/j.econmod.2012.11.035.

18) Afzal M, Farooq MS, Ahmad HK, Begum I, Quddus MA. Relationship between school education and economic growth in Pakistan: ARDL bounds testing approach to cointegration. Pakistan Economic and Social Review. 2010;48:39-60. Available from: http://pu.edu.pk/images/journal/pesr/PDF-FILES/3\% 20AFZAL\%20Relationship\%20e\%20School\%20Education\%20and\%20Economic\%20Growt\%2085.pdf.

19) Meo MS, Kumar B, Chughtai S, Khan VJ, Dost MKB, Nisar QA. Impact of Unemployment and Governance on Poverty in Pakistan: a Fresh Insight from Non-linear ARDL Co-integration Approach. Global Business Review. 2020. Available from: https://dx.doi.org/10.1177/0972150920920440.

20) All reports and publications . 2019. Available from: http://www.pbs.gov.pk/content/all-reports-and-publications.

21) ILO in Pakistan . 2019. Available from: https://www.ilo.org/islamabad/lang--en/index.htm.

22) The World Bank in Pakistan. . Available from: https://www.worldbank.org/en/country/pakistan/overview.

23) Dennis JE, Welsch RE. Techniques for nonlinear least squares and robust regression. Communications in Statistics - Simulation and Computation. 1978;7(4):345-359. Available from: https://dx.doi.org/10.1080/03610917808812083.

24) Björck Å. Numerical methods in matrix computations;vol. 59. Springer. 2015. Available from: http://218.194.248.217:8082/a01jbooks/N/25/5252.pdf.

25) Kemmer G, Keller S. Nonlinear least-squares data fitting in Excel spreadsheets. Nature Protocols. 2010;5(2):267-281. Available from: https://dx.doi.org/ 10.1038/nprot.2009.182. 